\title{
The effects of urban traffic plans on noise abatement: a case study
}

\author{
M. Gallo ${ }^{1}$, G. De Luca ${ }^{1}$ \& V. De Martinis ${ }^{2}$ \\ ${ }^{1}$ Department of Engineering, University of Sannio, Italy \\ ${ }^{2}$ Department of Civil, Architectural and Environmental Engineering, \\ University of Naples Federico II, Italy
}

\begin{abstract}
Traffic noise is a significant externality in urban areas that reduces the quality of life and may produce non-negligible effects on human health. The main factor responsible for traffic noise is individual transportation (cars and motorcycles) and the more congested the urban network, the higher the average level of traffic noise. An Urban Traffic Plan (UTP) is a tool for managing the urban mobility; in Italy the UTP is provided for under national laws and one of its objectives is noise abatement. The UTP manages the network (road directions, signal settings, etc.) without providing new infrastructures. In this paper, we test the effectiveness of UTPs in terms of noise abatement on a real case: the Urban Traffic Plan of Benevento. In this paper, we compare the estimated equivalent noise levels in several points of the town for the current scenario and for the (final) design scenario. Initial results show that, in order to evaluate the actual effectiveness of the UTP vis-à-vis traffic noise, some more comprehensive indicators have to be proposed: evaluating traffic noise reduction only in some points of the network cannot yield clear-cut results.
\end{abstract}

Keywords: traffic noise, urban traffic plan, sustainable mobility.

\section{Introduction}

Sustainable mobility is considered one of the main objectives of transportation planning, especially in urban areas, where congestion, air pollution and noise significantly lower the quality of life. Noise is one of the main externalities produced by road traffic; apart from a generic impact on the quality of life, traffic 
noise may produce serious effects on human health, annoyance and sleep disturbance. These effects have been extensively studied and reported [1-7].

In Italy, noise abatement is identified as one of the main objectives of Urban Traffic Plans (UTPs), together with (a) improvement in traffic circulation and (b) road safety, (c) reduction in air pollution and (d) energy saving. These objectives are explicitly laid down under Italian law by which implementation of a UTP is imposed on all towns and cities with over 30,000 inhabitants. The UTP is a tactical plan that should be updated every two years and should not consider infrastructural interventions (e.g. new roads) but only manage interventions on existing roads, on existing junctions (traffic signal parameters, kind of traffic regulations, etc.) and parking.

The Municipality of Benevento (southern Italy) designed a UTP mainly to reduce total travel times for road network users. In this paper, by means of some recent models proposed in the European Union, we test the impacts of this plan on traffic noise.

This paper is organised as follows: Section 2 examines the background to the problem; Section 3 examines the model adopted for evaluating traffic noise; Section 4 reports the results for the case study of Benevento and is followed by the conclusions in Section 5.

\section{Background}

Assessment and management of environmental noise is regulated in Europe by the European Directive 2002/49/EC [8] which defines the acoustic parameter for describing and quantifying noise; this parameter is the $L_{d e n}$ (Level day-eveningnight) and aims to standardise measurements in the European Union so as to make data from different areas comparable. This parameter is calculated as follows:

$$
L_{d e n}=10 \cdot \log _{10} \frac{1}{24} \cdot\left[12 \cdot 10^{\frac{L_{d}}{10}}+4 \cdot 10^{\frac{L_{e}+5}{10}}+8 \cdot 10^{\frac{L_{n}+10}{10}}\right]
$$

where:

$L_{d}$ is the equivalent noise level during the day (7:00-19:00);

$L_{e}$ is the equivalent noise level during the evening (19:00-23:00);

$L_{n}$ is the equivalent noise level during the night (23:00-7:00).

The unit of measurement for $L_{d e n}$ and for equivalent noise levels is $\mathrm{dB}(\mathrm{A})$. The European Directive allows the evening period to be reduced by one or two hours, consequently increasing daytime and/or night-time periods. In the literature, several models for estimating the equivalent noise level have been proposed. These models usually estimate the equivalent noise level according to variables such as traffic flow, road surface, average vehicle speed, distance of the receptor from the traffic lane, percentage of heavy trucks and kind of pavement. A review of the models proposed prior to 2001 can be found in [9]. As regards papers dealing with traffic noise produced by roads, some models and methods can be found in [10-20]. Several studies have focused on specific cases, including those by Lam and Tam [21], Klæboe et al. [22, 23], Ali and Tamura [24], Pamanikabud 
and Vivitjinda [25], Calixto et al. [26], Ali [27], Li and Tao [28], Piccolo et al. [29], Jamrah et al. [30], Cho and Mun [31], Murphy et al. [32], Oyedepo and Abdullahi [33], Pamanikabud and Tansatcha [34], Phan et al. [35], Agarwal and Swami [36], Mehdi et al. [37], Seong et al. [38], Di et al. [39], and Lam and Ma [40].

As for the numerous models for estimating the equivalent noise level from road traffic, (homogenised) hourly traffic flow is universally considered as an input variable, while most models consider mean speed and some consider other variables as well (kind of road pavement, road slope, road width, etc.); some models calculate noise at a fixed distance, while for others distance is an input variable. As regards the models and methods for estimating traffic flows and speeds, the literature is very extensive. However, a complete review lies beyond the scope of this paper and here we refer only to [41-44].

\section{The CNOSSOS-EU model}

A recent and advanced model for estimating noise produced by road traffic was developed in the EU project CNOSSOS [45]. This model calculates the sound power emission of a traffic flow as follows:

$$
L_{W^{\prime}, \text { eq }, \text { line }, i, m}=L_{W, i, m}+10 \cdot \log \cdot\left(f_{m} /\left(1000 \cdot v_{m}\right)\right)(\mathrm{dB})
$$

where:

$L_{W}$, eq,line, $i, m$ is the directional sound power per meter per hour per frequency band resulting from the vehicle flow;

$L_{W, i, m} \quad$ is the instantaneous directional sound power in "semi free-field" of a single vehicle;

$i \quad$ represents the octave band of frequency from $125 \mathrm{~Hz}$ to $4 \mathrm{kHz}$;

$m \quad$ represents the category of vehicles;

$f_{m} \quad$ is the steady traffic flow of vehicles of category $m(\mathrm{veh} / \mathrm{h})$;

$v_{m} \quad$ is the average speed of traffic flows $(\mathrm{km} / \mathrm{h})$.

There are four vehicle categories: 1) cars and light duty vehicles $\leq 3.5 \mathrm{t}$ (light); 2) duty vehicles and buses with two axles and twin tyres on the rear axle (medium);

3) heavy duty vehicles and buses with three or more axles (heavy); and

4) two-wheelers. In order to estimate the sound power emission of a single vehicle, two main noise sources are considered:

- $\quad$ rolling noise due to the tyre/road interaction;

- propulsion noise.

The general form of the sound power emitted by one of the sources is a function of the average speed $v_{m}$ as follows:

$$
L_{W, i, m}\left(v_{m}\right)=A_{i, m}+B_{i, m} \cdot f\left(v_{m}\right),
$$

where $f\left(v_{m}\right)$ is a logarithmic function in the case of rolling noise $(W R)$ and a linear function in the case of propulsion noise $(W P)$. 
For vehicles belonging to categories 1, 2 and 3 the sound power level is the sum of the two contributions:

$$
L_{W, i, m}\left(v_{m}\right)=10 \cdot \log \left(10^{L_{W R, i, m}\left(v_{m}\right) / 10}+10^{L_{W P, i, m}\left(v_{m}\right) / 10}\right) .
$$

For two-wheelers only propulsion noise is considered.

For rolling noise, the sound power level is expressed by:

$$
L_{W R, i, m}=A_{R, i, m}+B_{R, i, m} \cdot \log \left(v_{m} / v_{r e f}\right)+\Delta L_{W R, i, m}\left(v_{m}\right),
$$

where:

$A_{R, i, m}$ and $B_{R, i, m}$ are coefficients reported in Table 1;

$v_{\text {ref }} \quad$ is a reference speed equal to $70 \mathrm{~km} / \mathrm{h}$;

$\Delta L_{W R, i, m}$ is a correction term that considers the deviations from the reference conditions of the model.

The correction term is calculated as:

$$
\begin{aligned}
\Delta L_{W R, i, m}\left(v_{m}\right)= & \Delta L_{W R, \text { road }, i, m}\left(v_{m}\right)+\Delta L_{\text {studdedtyres }, i, m=1}\left(v_{m}\right)+ \\
& +\Delta L_{W R, a c c, i, m}+\Delta L_{W, \text { temp }}(\tau)
\end{aligned},
$$

where:

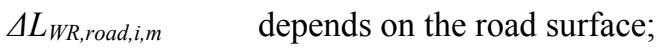

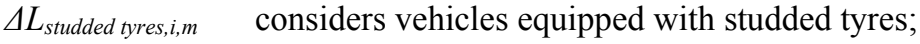

$\Delta L_{W R, a c c, i, m}$ considers the effects of rolling noise for acceleration when vehicles cross a signalised junction or a roundabout;

$\Delta L_{W, \text { temp }(\tau)} \quad$ is a correction term for an average temperature other than $20^{\circ} \mathrm{C}$ (reference temperature).

The methods for estimating the correction terms are reported in the cited CNOSSOS research report [45].

For propulsion noise, the sound power level is expressed by:

$$
L_{W P, i, m}\left(v_{m}\right)=A_{P, i, m}+B_{P, i, m} \cdot \frac{\left(v_{m}-v_{r e f}\right)}{v_{r e f}}+\Delta L_{W P, i, m}\left(v_{m}\right),
$$

where:

$A_{P, i, m}$ and $B_{P, i, m}$ are coefficients reported in Table 1;

$v_{\text {ref }} \quad$ is a reference speed equal to $70 \mathrm{~km} / \mathrm{h}$;

$\Delta L_{W P, i, m}$ is a correction term that considers the deviations from the reference conditions of the model.

The correction term is calculated as:

$$
\Delta L_{W P, i, m}\left(v_{m}\right)=\Delta L_{W P, \text { road }, i, m}\left(v_{m}\right)+\Delta L_{W P, a c c, i, m}+\Delta L_{W P, \text { grad }, i, m}\left(v_{m}\right),
$$

where:

$\Delta L_{W P, r o a d, i, m} \quad$ depends on the road surface; 
considers the effects of rolling noise for the acceleration when the vehicles cross a signalised junction or a roundabout;

$\Delta L_{W P, \text { grad,i,m }} \quad$ is a correction term that considers the effects of the road gradient.

The methods for estimating the correction terms are reported in the cited CNOSSOS research report [45].

Table 1: Coefficients of the CNOSSOS model [45].

\begin{tabular}{|c|c|c|c|c|}
\hline & \multicolumn{4}{|c|}{ Coefficients for category $m=1$ (cars) } \\
\hline $\begin{array}{c}\text { Octave band centre } \\
\text { frequency(Hz) }\end{array}$ & $A_{R}$ & $B_{R}$ & $A_{P}$ & $B_{P}$ \\
\hline 63 & 79.7 & 30.0 & 94.5 & -1.3 \\
\hline 125 & 85.7 & 41.5 & 89.2 & 7.2 \\
\hline 250 & 84.5 & 38.9 & 88.0 & 7.7 \\
\hline 500 & 90.2 & 25.7 & 85.9 & 8.0 \\
\hline 1000 & 97.3 & 32.5 & 84.2 & 8.0 \\
\hline 2000 & 93.9 & 37.2 & 86.9 & 8.0 \\
\hline 4000 & 84.1 & 39.0 & 83.3 & 8.0 \\
\hline 8000 & 74.3 & 40.0 & 76.1 & 8.0 \\
\hline
\end{tabular}

Having calculated the sound power levels for each frequency band, the A-weighted sound pressure level is calculated by summing all frequencies:

$$
L_{e q, T}=10 \cdot \log \sum_{i} 10^{\left(L_{W^{\prime}, i, m}+A_{i}\right) / 10},
$$

where:

$A_{i}$ indicates the A-weighting correction according to IEC 61672-1; $i$ is the frequency band index.

The CNOSSOS model also gives information for estimating sound propagation. In this paper, our tests will concern only the sound pressure levels on some roads in the case study.

\section{The case study}

We estimate the effects of an Urban Traffic Plan (UTP) on noise reduction in Benevento, a town in southern Italy with about 62,000 inhabitants. The network is represented by a supply model (see Figure 1) with 949 road segments (1,577 oriented links in the "Before" configuration), representing about $216 \mathrm{~km}$ of roads, 678 nodes and 80 centroids (66 internal and 14 external). 
The municipality of Benevento drafted the UTP after consulting the Department of Engineering of the University of Sannio. The UTP was developed within the following steps, some of which were performed in parallel:

1) Data and information collection. In this phase, all data and information necessary for implementing the plan were collected, such as the current transportation supply, available data on transportation demand, available maps, census data, etc.

2) Identification of the study area and zoning. In this phase, the study area was identified and then partitioned into traffic zones so as to identify a finite number of trip origins and destinations.

3) Implementation of the road transport supply model. In this phase, the model of the Benevento road network was constructed. The model was implemented in software Omnitrans 5 [46], adopted for simulating traffic flows and improving the OD matrices, generated in phase 5.

4) Traffic flow surveys. In this phase, an extensive survey of traffic flows was designed and carried out, as required for the phase of estimation and correction of the OD matrices.

5) Mobility demand estimation. In this phase the OD matrices were estimated through mathematical models; they summarise all trips that occur between the various zones of the town in different time periods. These matrices were improved by a correction procedure according to the traffic flows detected.

6) Road traffic simulation in the current state. In this phase the current configuration of the road transport system was simulated. This phase is necessary both to collect data required for comparing the new scenarios with the current one (initial scenario), and to verify the proper implementation of the supply model and the correct estimation of transport demand.

7) Proposal and comparison of new scenarios. In this phase different scenarios were proposed, simulated and compared with the current one from several standpoints (total travel times, consumption, emissions, etc.).

8) Choice of the final scenario. In this phase the final project was identified, described and compared in detail with the current situation.

The final scenario was chosen after simulating over 80 different scenarios, with the decisive factor being the estimation of user total travel time. The interventions regarded the direction of some road segments and the configuration and/or control of some intersections.

It was estimated that the new configuration of the road network should provide a reduction in terms of total travel time in a weekday of about 1,556 h (-9.44\%), equal to about $12.5 \mathrm{~h}$ /year saved for each circulating vehicle, a yearly reduction of about 862,000 litres of petrol and 562,000 litres of diesel fuel, an 8.0\% annual reduction in greenhouse gas emissions and about a $7.7 \%$ reduction in PM10 emissions.

In this paper, we verify whether there is also an improvement in terms of traffic noise, in addition to the other benefits listed above, estimating the parameter $L_{d e n}$ (Level day-evening-night), adopting the CNOSSOS model to estimate the equivalent noise levels. 


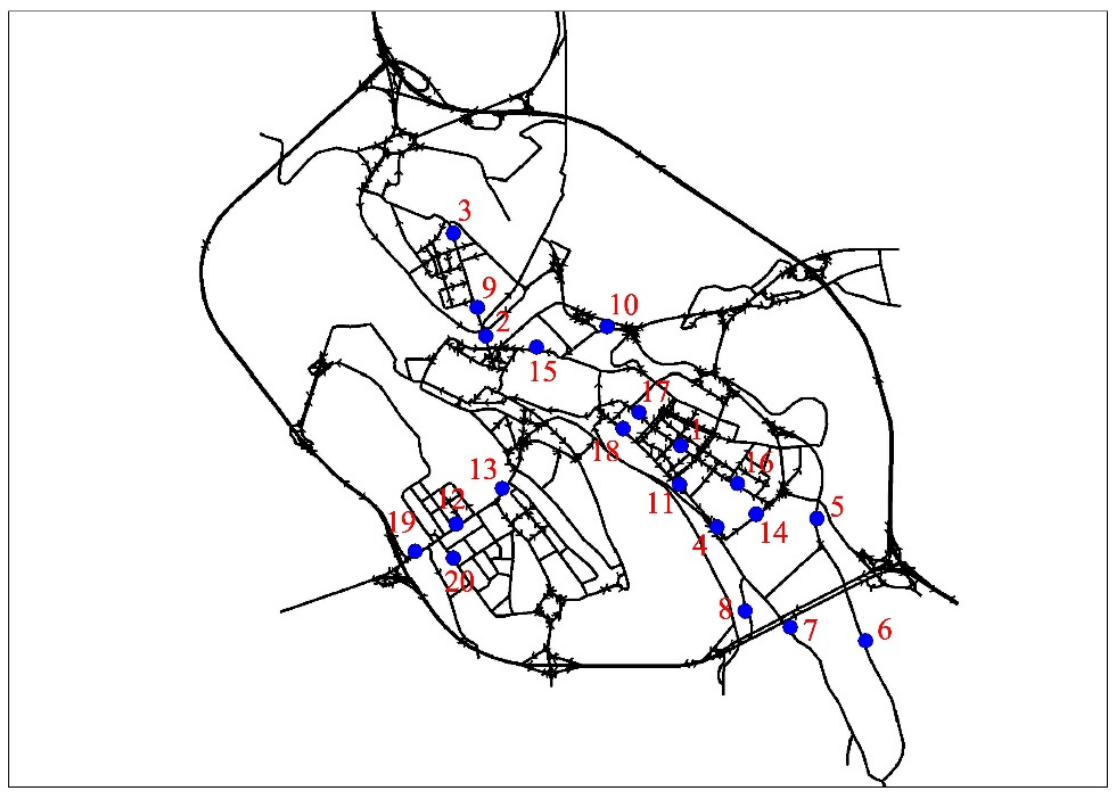

Figure 1: Road network of Benevento and test points.

The drafting of the UTP required implementation of the road network model (Figure 1) and estimation of transportation demand, represented by origindestination (OD) matrices. The origin destination matrices were estimated by following two steps: (i) using a mathematical model to obtain a first approximation of the OD matrices; (ii) correcting the obtained matrices using the traffic flows counted on several road sections. The traffic surveys were also able to estimate the variation in traffic flows during the day and the percentage of heavy vehicles.

There were four matrices generated, each of which can be adopted to estimate road traffic flows in some time periods:

- morning peak-hour OD matrix (MPH);

- afternoon peak-hour OD matrix (APH);

- daily off-peak hour OD matrix (DOPH);

- nightly off-peak hour OD matrix (NOPH).

We assume that each matrix is able to simulate traffic flows on the network in some hours of the day. Following the distinction between day, evening and night proposed by the European Directive 2002/49/EC [8] we assume the following scheme:

- day (7:00-19:00): 1 MPH, 2 APHs and 9 DOPHs;

- evening (19:00-23:00): 3 DOPHs and 1 NOPH;

- night (23:00-7:00): 1 DOPH and 7 NOPHs.

Each of the four OD matrices is assigned to the road network so as to estimate four sets of link traffic flows and speeds and hence, with the CNOSSOS methodology, four sets of $L_{e q}^{h}$, denoted by: $L_{e q}^{M P}, L_{e q}^{A P}, L_{e q}^{D O P}$ and $L^{N O P}$. 
Under these assumptions, we can write:

$$
\begin{gathered}
L_{d e n}=10 \cdot \log _{10} \frac{1}{24} \cdot\left[1 \cdot 10^{\frac{L^{M P} e_{e q}}{10}}+2 \cdot 10^{\frac{L^{A P}{ }_{e q}}{10}}+9 \cdot 10^{\frac{L^{D O P} e_{e q}}{10}}+3 \cdot 10^{\frac{L^{D O P} e_{e q, J+5}}{10}}+\right. \\
\left.+1 \cdot 10^{\frac{L^{N O P_{e q}+5}}{10}}+1 \cdot 10^{\frac{L^{D O P} e_{e q}+10}{10}}+7 \cdot 10^{\frac{L^{N O P_{e q}+10}}{10}}\right]
\end{gathered}
$$

We estimated the values of $L_{d e n}$ in 20 points of the network before and after the UTP, assuming flows and speeds obtained by the simulation model. In these tests we considered only the flows of personal cars, the main vehicle type on the urban network of Benevento.

The locations of the test points are reported in Figure 1 and the numerical results are summarised in Table 2 .

Table 2: Numerical results.

\begin{tabular}{|c|c|c|c|}
\hline Test point & $L_{\text {Den }}$ Before & $L_{\text {Den }}$ After & After-Before \\
\hline 1 & 70.696 & 71.660 & 0.964 \\
\hline 2 & 72.678 & 73.623 & 0.946 \\
\hline 3 & 70.606 & 70.983 & 0.377 \\
\hline 4 & 69.623 & 69.737 & 0.114 \\
\hline 5 & 74.520 & 74.250 & -0.270 \\
\hline 6 & 72.698 & 72.531 & -0.167 \\
\hline 7 & 72.973 & 72.339 & -0.633 \\
\hline 8 & 68.825 & 68.973 & 0.148 \\
\hline 9 & 71.372 & 71.306 & -0.065 \\
\hline 10 & 69.652 & 69.218 & -0.434 \\
\hline 11 & 71.464 & 71.455 & -0.008 \\
\hline 12 & 71.511 & 71.385 & -0.125 \\
\hline 13 & 74.332 & 74.175 & -0.157 \\
\hline 14 & 73.917 & 73.525 & -0.392 \\
\hline 15 & 65.286 & 66.948 & 1.662 \\
\hline 16 & 75.106 & 75.015 & -0.091 \\
\hline 17 & 71.623 & 71.742 & 0.119 \\
\hline 18 & 72.460 & 72.622 & 0.163 \\
\hline 19 & 72.422 & 72.276 & -0.146 \\
\hline 20 & 70.827 & 71.151 & 0.324 \\
\hline
\end{tabular}

The results show that in some points, corresponding to some links of the urban network, we obtain a reduction in traffic noise (11 points) and in others an increase (9 points). The differences are generally lower than $\pm 2 \mathrm{~dB}(\mathrm{~A})$.

These initial results are unable to provide a definitive response on the effects of the UTP on traffic noise. In order to evaluate the actual effects, we have to consider some indicators that can be applied on the whole network and that also consider the exposure of the inhabitants to different noise levels and/or the level of protection from noise in different urban areas. In future research, we will 
investigate other approaches that may be able to estimate the variation in traffic noise on the whole network, with a view to proposing a general indicator that can be used to evaluate the goodness of UTP scenarios.

\section{Conclusions}

In this paper, we estimated the effects of an Urban Traffic Plan on traffic noise reduction, applying the model developed within the CNOSSOS EU Project to a real case study. Initial results show that in different points of the network the estimated traffic noise can be lower or higher than the current network configuration. The results highlighted the need to propose other, more comprehensive, indicators that can be used to estimate the effects of the UTP on traffic noise. Such indicators should take account of the traffic noise on the whole network and of the people exposed to traffic noise. Future research will be designed to propose such indicators and to verify the reliability of the CNOSSOS model with real traffic data and traffic noise surveys.

\section{References}

[1] Öhrström, E., Effects of low levels of road traffic noise during the night: a laboratory study on number of events, maximum noise levels and noise sensitivity. Journal of Sound and vibration, 179, pp. 603-615, 1995.

[2] Heinonen-Guzejev, M., Vuorinen, H.S., Kaprio, J., Heikkilag, K. \& Mussalo-Rauhamaa, H., Self-Report of Transportation noise exposure, annoyance and noise sensitivity in relation to noise map information. Journal of Sound and vibration, 234, pp. 191-206, 2000.

[3] Ouis, D., Annoyance from Road Traffic Noise: a Review. Journal of Environmental Psychology, 21, pp. 101-12, 2001.

[4] Moriharaa, T., Satob, T. \& Yanoc, T., Comparison of dose-response relationships between railway and road traffic noises: the moderating effect of distance. Journal of Sound and vibration, 277, pp. 559-565, 2004.

[5] Franco, V., Garraín, D. \& Vidal, R., Methodological proposals for improved assessments of the impact of traffic noise upon human health. Int $J$ Life Cycle Assess, 15, pp. 869-882, 2010.

[6] Fyhri, A. \& Aasvang, G.M., Noise, sleep and poor health: Modeling the relationship between road traffic noise and cardiovascular problems. Science of the Total Environment, 408, pp. 4935-4942, 2010.

[7] Pirrera, S., De Valck, E. \& Cluydts, R., Nocturnal road traffic noise: a review on its assessment and consequences on sleep and health. Environment International, 36, pp. 492-498, 2010.

[8] European Commission, 'Directive 2002/49/EC of the European Parliament and the Council of 25 June 2002 relating to the assessment and management of environmental noise'. Official Journal of the European Communities, L 189/12, 18.7.2002.

[9] Steele, C., A critical review of some traffic noise prediction models. Applied Acoustics, 62, pp. 271-287, 2001. 
[10] Bendtsen, H., The Nordic prediction method for road traffic noise. The Science of the Total Environment, 235, pp. 331-338, 1999.

[11] Cirianni, F. \& Leonardi, G., The application of a neural network on a study of noise pollution in urban transport: a case in Villa S. Giovanni, In Air Pollution XII, WIT press, Southampton, UK, pp. 559-570, 2004.

[12] Tansatcha, M., Pamanikabud, P., Brown, A.L. \& Affum, J.K., Motorway noise modelling based on perpendicular propagation analysis of traffic noise. Applied Acoustics, 66, pp. 1135-1150, 2005.

[13] Gundogdu, O., Gokdagb, M. \& Yuksel, F., A traffic noise prediction method based on vehicle composition using genetic algorithms. Applied Acoustics, 66, pp. 799-809, 2005.

[14] Can, A., Leclercq, L. \& Lelong, J., Dynamic estimation of urban traffic noise: Influence of traffic and noise source representations. Applied Acoustics, 69, pp. 858-867, 2008.

[15] Pamanikabud, P., Tansatcha, M. \& Brown, A.L., Development of a highway noise prediction model using an Leq20 s measure of basic vehicular noise. Journal of Sound and Vibration, 316, pp. 317-330, 2008.

[16] Rajakumara, H.N. \& Gowda, R.M.M., Road Traffic Noise Prediction Model under Interrupted Traffic Flow Condition. Environ Model Assess, 14, pp. 251-257, 2009.

[17] Hamet, J.F., Besnard, F., Doisy, S., Lelong, J. \& le Duc, E., New vehicle noise emission for French traffic noise prediction. Applied Acoustics, 71, pp. 861-869, 2010.

[18] Makarewicz, R. \& Gałuszka, M., Road traffic noise prediction based on speed-flow diagram. Applied Acoustics, 72, pp. 190-195, 2011.

[19] Rahmani, S., Mousavi, S.M. \& Kamali, M.J., Modeling of road-traffic noise with the use of genetic algorithm. Applied Soft Computing, 11, pp. 1008-1013, 2011.

[20] Cirianni, F. \& Leonardi, G., Environmental modeling for traffic noise in urban area. American Journal of Environmental Science, 8, pp. 345-351, 2012.

[21] Lam, W.K.H. \& Tam, M.L., Reliability analysis of traffic estimates in Hong Kong. Transportation Research Part D, 3, pp. 239-248, 1998.

[22] Klæboe, R., Kolbenstvedt, M., Clench-Aas, J. \& Bartonova, A., Oslo traffic study part 1: an integrated approach to assess the combined effects of noise and air pollution on annoyance. Atmospheric Environment, 34, pp. 4727-4736, 2000.

[23] Klæboe, R., Amundsen, A.H., Fyhri, A. \& Solberg, S., Road traffic noise the relationship between noise exposure and noise annoyance in Norway. Applied Acoustics, 65, pp. 893-912, 2004.

[24] Ali, S.A. \& Tamura, A., Road traffic noise mitigation strategies in Greater Cairo. Egypt. Applied Acoustics, 63, pp. 1257-1265, 2002.

[25] Pamanikabud, P. \& Vivitjinda, P., Noise prediction for highways in Thailand. Transportation Research Part D, 7, pp. 441-449, 2002.

[26] Calixto, A., Diniz, F.B. \& Zannin, P.H.T., The statistical modeling of road traffic noise in an urban setting. Cities, 20, pp. 23-29, 2003. 
[27] Ali, S.A., Investigation of the dose-response relationship for road traffic noise in Assiut, Egypt. Applied Acoustics, 65, pp. 1113-1120, 2004.

[28] Li, B. \& Tao, S., Influence of expanding ring roads on traffic noise in Beijing City. Applied Acoustics, 65, pp. 243-249, 2004.

[29] Piccolo, A., Plutino, D. \& Cannistraro, G., Evaluation and analysis of the environmental noise of Messina, Italy. Applied Acoustics, 66, pp. 447-465, 2005.

[30] Jamrah, A., Al-Omari, A. \& Sharabi, R., Evaluation of traffic noise pollution in Amman, Jordan. Environmental Monitoring and Assessment, 120, pp. 449-525, 2006.

[31] Cho, D.S. \& Mun, S., Development of a highway traffic noise prediction model that considers various road surface types. Applied Acoustics, 69, pp. 1120-1128, 2008.

[32] Murphy, E., King, E.A. \& Rice, H.J., Estimating human exposure to transport noise in central Dublin, Ireland, Environment International, 35, pp. 298-302, 2009.

[33] Oyedepo, O.S. \&·Abdullahi, A.S., Evaluation and analysis of noise levels in Ilorin metropolis, Nigeria. Environ Monit Assess, 160, pp. 563-577, 2010.

[34] Pamanikabud, P. \& Tansatcha, M., 3D analysis and investigation of traffic noise impact from a new motorway on building and surrounding area. Applied Acoustics, 71, pp. 1185-1193, 2010.

[35] Phan, H.Y.T., Yano, T., Sato, T. \& Nishimura, T., Characteristics of road traffic noise in Hanoi and Ho Chi Minh City, Vietnam. Applied Acoustics, 71, pp. 479-485, 2010.

[36] Agarwal, S. \& Swami, B.L., Comprehensive approach for the development of traffic noise prediction model for Jaipur city. Environ Monit Assess, 172, pp.113-120, 2011.

[37] Mehdi, M.R., Kim, M., Seong, J.C. \& Arsalan, M.H., Spatio-temporal patterns of road traffic noise pollution in Karachi, Pakistan. Environment International, 37, pp. 97-104, 2011.

[38] Seong, J.C., Park, T.H., Ko, J., H. Chang, S.I., Kim, M., Holt, J.B. \& Mehdi, M.R., Modeling of road traffic noise and estimated human exposure in Fulton County, Georgia, USA. Environment International, 37, pp. 1336-1341, 2011.

[39] Di, C., Liu, X., Lin, Q., Zheng, Y. \& He, L., The relationship between urban combined traffic noise and annoyance: An investigation in Dalian, north of China. Science of the Total Environment, 432, pp. 189-194, 2012.

[40] Lam, K.-C. \& Ma, W.-C., Road complexes built at different times between 1950 and 2000 in Hong Kong. Applied Acoustics, 73, pp. 1112-1120, 2012.

[41] Cantarella, G.E., A general fixed-point approach to multimodal multi-user equilibrium assignment with elastic demand. Transportation Science, 31, pp. 107-128, 1997.

[42] Cascetta, E., Transportation systems analysis: models and applications, Springer: New York, 2009. 
[43] D’Acierno, L., Montella, B. \& De Lucia, F., A stochastic traffic assignment algorithm based on Ant Colony Optimisation. Lecture Notes in Computer Science, 4150, pp. 25-36, 2006.

[44] Ben-Elia, E., Di Pace, R., Bifulco, G.N. \& Shiftan, Y., The impact of travel information's accuracy on route-choice. Transportation Research Part $C$, 26, pp. 146-159, 2013.

[45] Kephalopoulos, S., Paviotti, M., Anfosso-Lédée, F., Common Noise Assessment Methods in Europe (CNOSSOS-EU). EUR 25379 EN, 2012.

[46] Omnitrans Transport Planning Software. Omnitrans International BV, 2010. 